\title{
Idéias e política externa: a atuação brasileira na Liga das Nações e na ONU ${ }^{1}$
}

\section{ALEXANDRA DE MELLO E SILVA*}

\section{1 - Os Estudos sobre Política Externa Brasileira: a negligência do fator cognitivo}

No Brasil, os estudos sobre relações internacionais e política externa foram marcados, inicialmente, pelo predomínio da História Diplomática de caráter tradicional, oriunda seja de autores profundamente ligados ao exercício mesmo da diplomacia ou ainda da necessidade de preparação de quadros burocráticos direta ou indiretamente associados à implementação da política externa, como é o caso dos diplomatas e militares. Como observam Cervo (1992) e Almeida (1993), foi somente a partir dos anos 60/70 que tais estudos começaram a se configurar em um campo acadêmico propriamente dito, cuja produção se deslocou progressivamente das instâncias governamentais para os Departamentos Universitários².

Por sua vez, essa institucionalização tardia da pesquisa universitária teve repercussões não apenas sobre as temáticas e enfoques teóricos dominantes nessa área, como também no fato de que o debate acadêmico tendeu a privilegiar dimensões normativas e prescritivas. Fonseca Jr. (1989) identifica o surgimento, nas décadas de 1950/60, de dois modelos básicos de análise da política externa. No modelo da "nação incompleta", que tem por substrato teórico as teorias marxistas do imperialismo e a teoria da dependência, a ênfase recai sobre o caráter dependente de nossa economia e sua inserção periférica no sistema capitalista mundial. Na vertente mais determinista deste modelo, a análise da política externa não tem importância em si mesma, havendo espaço, contudo, para o tratamento das relações internacionais do Brasil, vistas como ponto de convergência entre os interesses do Centro e das elites internacionalizadas da periferia. Já na vertente não determinista, a situação de dependência se constitui em um condicionamento da política exterior, que pode variar histórica e geograficamente em função de fatores estruturais de ordem interna e externa (Lima, 1992). ${ }^{3}$ 
O segundo modelo, o do "baluarte do Ocidente”, tem por base teórica o paradigma realista e sua concepção do sistema internacional como arena anárquica de Estados soberanos acima dos quais não paira nenhuma autoridade, e onde a cooperação entre estes só pode ocorrer de forma ad hoc. Este modelo foi desenvolvido, fundamentalmente, pelo pensamento geopolítico, concentrando seu foco analítico nos conflitos estratégicos que moldam a estrutura do sistema internacional para, a partir daí, derivar estratégias de ação diplomática fundadas na noção de uma "aliança especial" com os EUA. ${ }^{4}$

Lima (1992) identifica ainda um terceiro modelo que, de fato, retira substratos teóricos de ambos os modelos anteriores, fundindo a matriz realista aos conceitos cepalinos de centro/periferia e de desenvolvimento desigual e combinado da economia capitalista mundial. Formulado basicamente por Hélio Jaguaribe (1958) e Araújo Castro (1982), este modelo exerceria enorme influência seja na análise acadêmica ou nas formulações oficiais da diplomacia brasileira. Tal aspecto não é de se estranhar pois, como observa Fonseca Jr., a reflexão intelectual, nesse campo, acompanhou quase sempre as prioridades da política externa, de tal forma que as "angústias" do pesquisador estavam sempre muito próximas das dos formuladores oficiais, sendo uma análise da produção acadêmica sempre muito reveladora do que pensava e fazia o Estado.

Assim, é também bastante significativo que o surgimento, na década de 70 , de uma nova safra de estudos sobre política externa tenha ocorrido simultaneamente a um processo de diversificação e autonomização da própria ação diplomática, que veio evidenciar um conjunto de insuficiências teóricas e empíricas nos modelos de interpretação até então vigentes. Partindo da premissa comum de que, em um país periférico como o Brasil, os elementos de dependência e/ou autonomia não são excludentes, mas de fato se conjugam em um mesmo projeto de política externa, tais estudos começam a destacar o grau de complexidade presente nos processos de formulação e implementação de nossa diplomacia, evidenciado seja no plano dos condicionamentos internos (demandas da política econômica, disputas entre agências burocráticas, interação entre atores estatais e não estatais) ou externos (grau de "permissibilidade" ou rigidez do sistema internacional). Nesse sentido, as explicações monocausais foram, de modo geral, abandonadas, cedendo lugar a um universo crescente de variáveis explicativas. ${ }^{5}$ Por outro lado, é importante destacar que, até como conseqüência mesma desse alargamento do foco analítico, na maioria desses estudos persiste uma grande imprecisão conceitual no tocante à delimitação da especificidade dos processos de formulação, decisão e implementação, tratados todos, quase sempre, como um processo único (Pinheiro, 1994). De fato, essa imprecisão reflete um diálogo ainda incipiente entre a produção acadêmica brasileira e a literatura internacional sobre teoria das relações internacionais, onde a subárea de análise de política externa, constituída em fins dos anos 50, desenvolveu todo um aparato teórico-metodológico que visa à distinção entre aqueles conceitos. 
Uma outra insuficiência, em grande parte derivada da primeira, é que, mesmo nas análises que dedicam atenção à formulação da política externa, a ênfase recai sobre os fatores de natureza tangível - políticos, econômicos, estratégicos , buscando-se delimitar o peso das diferentes agências burocráticas que participam dessa formulação e/ou o padrão de interação entre estas e grupos de interesse não estatais. Os fatores de ordem cognitiva, eventualmente mencionados sob o conceito genérico de "percepções”, não chegam a adquirir o status de uma variável explicativa. Persiste, portanto, uma lacuna empírica e analítica sobre a dimensão cognitiva da formulação diplomática, expressa nas "visões de mundo" portadas pelos policymakers; e sobre qual o peso que essa variável deve ou pode ter na explicação da atuação diplomática do Brasil. Tais “visões de mundo”, por sua vez, se manifestam através de um universo mais ou menos codificado de idéias ${ }^{6}$ a respeito do sistema internacional e da inserção de uma determinada nação nesse último (Vertzberger, 1990).

Lima (1994) destaca a importância da dimensão cognitiva ao delinear a existência de dois paradigmas de política externa, concebidos como teorias de ação diplomática constituídas por um conjunto articulado de idéias-base que são, de fato, mapas cognitivos, ajudando o diplomata a dar sentido à complexidade do mundo que o rodeia. O paradigma americanista consolidou-se a partir do que se convencionou chamar de "a herança de Rio Branco", qual seja, a concepção de que um relacionamento especial com os EUA deveria se constituir no principal eixo de nossa diplomacia. Seja em sua vertente pragmática ou ideológica, esse paradigma foi hegemônico nas formulações da política externa brasileira até a década de 60. Por volta dessa época, assiste-se à emergência do paradigma globalista, que enfatiza a necessidade de universalização da política externa e de sua libertação dos alinhamentos político-estratégicos concebidos aprioristicamente. A relação com os EUA deixa de ser vista como um instrumento para o aumento do poder de barganha do país no plano externo; ao contrário, esse poder deve ser construído a partir de uma inserção global e utilizado para assegurar relações menos assimétricas com a potência hegemônica. Subtraído o movimento de inflexão da política externa vivenciado durante os primeiros governos militares, quando se assiste a um retorno ao americanismo, a partir de meados da década de 70 o paradigma globalista voltaria a ser hegemônico, assim permanecendo até o final dos anos 80 . Desde então, a convergência entre novos condicionamentos internos (redemocratização política associada à crise do modelo de desenvolvimento) e externos (fim da Guerra Fria e aprofundamento do processo de globalização) criou as condições para o forte questionamento do globalismo e uma revisão de diversas posturas assumidas pela diplomacia brasileira. De fato, poderíamos nos perguntar se não estamos assistindo à emergência de um novo paradigma, que combina elementos de "americanismo" - como a concepção da importância da manutenção de um relacionamento positivo com os EUA - e elementos de "globalismo" - 
como a persistência da visão do Brasil como um país complexo e singular, com interesses políticos e econômicos diversificados e, portanto, destinado a uma inserção internacional universalista e proeminente.

É interessante observar, contudo, que ambos os paradigmas incorporam um “acervo diplomático permanente”, ou seja, um conjunto de normas e posturas - pacifismo, não-intervencionismo, defesa da igualdade soberana das nações, respeito ao Direito Internacional - que são percebidos como patrimônio histórico e estariam intrinsecamente associados ao comportamento internacional do país. Como observa Cervo (1994), esse "acumulado histórico", fundado sobre tradições que remontariam à Independência e ao Império, é também um indicador de "tendências” que perpassam as sucessivas mudanças e inflexões da política exterior.

Além disso, em ambos os paradigmas pode-se delinear claramente a persistência da tradição realista no tocante às visões sobre a natureza do sistema internacional. Evidentemente, não se pode esquecer do papel cumprido pelo Itamaraty na sistematização e transmissão desse "acervo" tendo em vista os recursos organizacionais de que dispõe, tais como o alto grau de burocratização e de identidade organizacional, o forte insulamento e a relativa autonomia decisória. Mesmo assim, cabe observar que a cristalização da maioria dessas normas e posturas ocorreu nas primeiras décadas do século, quando o grau de profissionalização da diplomacia e de autonomia e identidade corporativa do Itamaraty eram bastante reduzidos (Cheibub, 1982).

Nesse sentido, parece-nos que uma investigação mais acurada a respeito do conteúdo e dos canais de propagação desse "acervo diplomático permanente”, bem como de outras crenças que, ainda hoje, têm se revelado relativamente permanentes na cultura política nacional - como o desejo de converter o país em um ator importante na política internacional e a noção de que a política externa paira acima do jogo político doméstico - é fundamental para a compreensão de como se formam e operam as "visões de mundo" da diplomacia brasileira.

\section{2 - O quadro analítico: percepções, idéias e interesses}

No final dos anos 50, a insatisfação generalizada com o realismo levou ao desenvolvimento de uma subárea na teoria das relações internacionais que ficou conhecida como "análise de política externa” (foreign policy analysis). Criticando as concepções realistas do Estado como ator unitário, racional e com preferências dadas em termos de comportamento internacional, o novo paradigma buscava a “abertura da caixa preta”, através do desvendamento das variáveis que, dentro e fora do Estado, atuavam na formulação de políticas externas diferenciadas (Smith, 1988).

Uma das vertentes daquela literatura concentrou-se, inicialmente, nos estudos sobre processos decisórios, deslocando-se posteriormente para uma análise 
dos mecanismos de cognição e percepção que envolvem o processamento da informação. A dimensão subjetiva do processo que resultava em uma determinada decisão de política externa passou então a ser considerada sob a forma das percepções portadas pelos tomadores de decisão (decision makers), que, por sua vez, se originavam de uma determinada "definição da situação". Reconhecia-se, portanto, que o processamento das informações acerca do mundo "objetivo" podia ser imperfeito, e que entre o mundo real e a mente do indivíduo impunha-se uma mediação. A formulação dos conceitos de "ambiente psicológico" - referente às representações mentais - e "ambiente operacional" - referente ao ambiente real - visava justamente destacar a importância daquela mediação (Vertzberger, 1990).

Desde então, a literatura especializada desenvolveu uma série de abordagens para tratar dos elementos cognitivos que incidem sobre a formulação de políticas. "Imagens”, "mapas cognitivos”, "sistemas de crenças”, “códigos operacionais" e "lições do passado" são alguns desses conceitos7", mas o fato é que todos eles têm uma preocupação central: a "brecha” existente entre a realidade - supostamente "objetiva" - do ambiente operacional e sua representação "subjetiva" na mente do policymaker. Portanto, todos têm alguma ligação com os trabalhos sobre percepção/má percepção (perception/misperception), e podem ser classificados como uma abordagem cognitiva ou psicológica das relações internacionais (Smith, 1988).

Os conceitos de percepção e "má percepção" estão diretamente relacionados à noção de "definição da situação" e sua conexão com o processo decisório. Assim, a "má percepção" é definida e mensurada em termos da discrepância entre o mundo real (objetivo) e sua representação mental (subjetiva), a qual levaria à escolha de estratégias de ação inadequadas e fadadas ao fracasso. Por contraste, uma percepção "correta” da realidade teria por conseqüência a adequação entre estratégia e objetivos (Brecher, citado em Smith, 1988). Contudo, a maior parte dos estudos nesse campo concentrou-se nos aspectos estáticos e de curto prazo da percepção, cujo recorte empírico era quase sempre constituído pela análise de situações de crise (Vertzberger, 1990). O termo "definição da situação" já é, nesse sentido, revelador, na medida em que remete, metodologicamente, ao “congelamento" de uma situação específica em um momento determinado. $\mathrm{Na}$ verdade, como observa Herz (1994), a ênfase na “definição da situação” resultou de uma extrema concentração desses estudos sobre a tomada de decisões e as ações do Estado daí resultantes. A preocupação, nesse caso, centrava-se sobre as "patologias" do processo decisório, conceituadas então como produto de misperceptions.

Vertzberger também identifica uma outra insuficiência nos estudos sobre percepção/má percepção, ligada ao seu caráter excessivamente descritivo e à sua dificuldade em distinguir entre causas e sintomas das mispercetions. Imagens “deformadas” desenvolvidas por um determinado ator em relação a outros atores 
na arena internacional não podem ser tratadas como causas mas sim como sintomas de má percepção, na medida em que freqüentemente baseiam-se em crenças normativas para as quais não existem comprovações lógicas ou empíricas. Além disso, policymakers possuem não apenas crenças normativas mas também crenças causais ou instrumentais - isto é, crenças relativas a relações de causa e efeito, que fornecem estratégias a serem perseguidas para a realização de determinadas preferências (Elster, 1994; Keohane e Goldstein, 1993; Goldstein, citada em Jacobsen, 1996). Rotular crenças de ambos os tipos como "falsas" ou “discrepantes” em relação à realidade não dispensa o pesquisador da tarefa de explicar porque tais crenças influenciam o comportamento dos decision makers (Yee, 1996). ${ }^{8}$

Posteriormente, uma nova vertente da literatura especializada passou a dedicar-se à análise do impacto de idéias sobre a formação de políticas, sobretudo no tocante à política externa e à política econômica. As características dessa nova vertente são, de um lado, um total abandono das preocupações quanto ao gap cognitivo que tanto marcaram os estudos sobre perception/mispercetion; e, de outro, uma insatisfação generalizada quanto à incapacidade do neorealismo e de modelos de escolha racional, como a teoria dos jogos, em dar conta da complexidade cognitiva do processo de formação de políticas (Keohane e Goldstein, 1993; Yee, 1996). Como observam Keohane e Goldstein, aquela literatura se desenvolveu, inicialmente, a partir de posições distintas. Na posição racionalista (que, na teoria das relações internacionais, compreende tanto o realismo quanto o liberalismo institucional), as idéias não têm importância como mecanismo causal, tendo em vista que interesses e preferências são dados e os atores, agindo de forma racional, antecipam o resultado de suas ações. Aqui, idéias são apenas “cabides” (hooks) que fornecem rationales intelectuais e/ou políticas para a propagação e legitimação de interesses. Já na posição reflexivista, crenças e idéias desempenham papel central em uma "concepção cognitiva e intersubjetiva do processo pelo qual identidades e interesses são endógenos à interação”, por oposição à postura racionalista- behaviorista que os vê como exógenos. (Idem, p. 5) Trata-se, portanto, de investigar não apenas as estratégias desenvolvidas por atores para atingir determinados interesses mas como preferências e identidades são construídas e moldadas. ${ }^{9}$

Mais recentemente, esse debate evoluiu para um novo round dentro do próprio campo racionalista. De um lado, autores identificados com a perspectiva da ação racional, como no caso dos próprios Keohane e Goldstein, passaram a reconhecer a importância das idéias sem que com isso se tenha que abandonar o postulado de que os agentes comportam-se racionalmente guiados por seu autointeresse. De outro, em seu esforço para fugir da conceituação de idéias como meros "cabides", as análises dedicadas a defender a influência independente das idéias sobre a formação de políticas acabaram por enveredar por uma armadilha 
teórica e metodológica. Como observa Jacobsen (1995), o imbroglio se deveu ao fato de que o argumento-base - "que o poder das idéias em si mesmo explica a sua aceitação" - primeiro tem que demonstrar que interesses são interpenetrados por idéias, para então demonstrar que essas mesmas idéias exercem uma influência não "contaminada" pelos interesses que, como demonstrado previamente, elas interpenetram (p. 286). Trata-se, portanto, de uma falha em reconhecer que idéias e interesses só podem ser concebidos como "entidades separadas" de um ponto de vista analítico, e não empírico, e de que análises centradas sobre a influência de idéias se constituem em um suplemento valioso - e não, necessariamente, em uma alternativa excludente - a modelos baseados nos supostos da ação racional.

Caracterizada por estudos de caso, essa literatura vem se preocupando em delinear os diferentes mecanismos causais através dos quais idéias produzem impactos significativos sobre a formulação e adoção de políticas. Uma avaliação bibliográfica geral indica a ênfase sobre os mecanismos institucionais, como é o caso, por exemplo, das análises de Hall (1989) e Goldstein (citada em Jacobsen, 1995; e Yee, 1996).

O primeiro autor constrói, de fato, uma tipologia de variáveis explicativas a partir dos diversos estudos de caso contidos em seu livro sobre a influência internacional do keynesianismo na adoção de políticas econômicas nacionais antes e durante o pós-guerra, assinalando a existência de explicações centradas sobre o papel dos experts (economist-centered) ${ }^{10}$ e do Estado (state-centered). Nas análises economist-centered, o foco explicativo recai sobre o impacto teórico e acadêmico do pensamento de Keynes sobre os economistas e a posição ocupada por estes últimos dentro do processo de formação de políticas. Já nas análises state-centered, a explicação principal é buscada nos diferentes arranjos e ethos burocrático-administrativos de cada Estado e sua maior ou menor permeabilidade à absorção de novas idéias.

Um outro exemplo de mecanismos causais institucionais pode ser encontrado na análise de Goldstein sobre a política comercial norte-americana, que ressalta o papel das idéias quando essas se incorporam a instituições sob a forma de regras organizacionais legalmente prescritas, procedimentos, processos de recrutamento e socialização, produção legislativa etc. Como observa a autora, mesmo que a institucionalização, em algum ponto do tempo, tenha ocorrido não porque as idéias em si eram mais “poderosas” ou persuasivas, mas sim porque correspondiam aos interesses do mais poderoso, aqueles interesses podem desaparecer no tempo enquanto que as idéias institucionalizadas continuam a influenciar a formulação de políticas, às vezes por décadas ou gerações (Keohane e Goldstein, 1993, pp. 20/21).

Voltando a Hall, este autor nos oferece ainda um tipo de mecanismo causal não institucional nas análises que ele classifica como coalition-centered, por conferirem importância central à ressonância encontrada pelas prescrições 
keynesianas junto a grupos sociais relevantes e à sua eficácia em forjar e/ou consolidar novas coalizões políticas. Um outro exemplo de mecanismo causal não institucional é aquele delineado por Keohane e Goldstein ao ressaltarem o papel de idéias enquanto "pontos focais" (focal points) ou "mapas de estrada” (road maps). Nesse caso, problemas ligados à ação coletiva, ou ainda a incerteza dos agentes em relação ao contexto em que atuam, podem ressaltar a importância de um conjunto articulado de crenças normativas e causais que balize a seleção de estratégias.

Cabe lembrar, contudo, que como bem observa Hall ao elaborar a sua tipologia, a delimitação e o isolamento desses diferentes mecanismos causais obedece a um critério sobretudo analítico, na medida em que os estudos empíricos nos revelam que, na prática, dois ou mais mecanismos causais podem estar operando simultaneamente, ou se sucedendo ao longo do tempo. Na análise de Ikenberry (1993) sobre o papel do keynesianismo na reordenação do sistema econômico internacional do pós-guerra, podemos verificar a existência de pelo menos três mecanismos causais: o economist-centered - a influência das idéias de Keynes sobre a comunidade acadêmica e profissional dos economistas norte-americanos e britânicos; o state-centered - a possibilidade que tais idéias abriram ao forjamento de novas alianças entre setores da burocracia dos dois países, de forma a isolar os setores adeptos do antigo laissez-faire; e, ainda, o coalition-centered - a importância do keynesianismo na consolidação de novas coalizões políticas, identificadas com o Welfare State dominante em ambos os países no pós-Guerra.

Note-se, porém, que idéias não estão sendo tratadas aqui como meros “cabides” para a maximização de interesses (no caso, um sistema econômico internacional aberto mas também baseado em mecanismos regulatórios monetários e financeiros) ou, para citar as palavras de Hall, como um fator que, ao entrar na arena política, simplesmente se coloca "por cima” dos outros fatores já presentes (p.366). Por se apoiar em um conjunto de crenças causais e normativas novo e heterodoxo a respeito dos objetivos e instrumentos da política econômica (pleno emprego, crescimento econômico, medidas governamentais anticíclicas via administração da demanda agregada), o keynesianismo contribuiu para alterar os próprios termos do discurso político tanto no plano doméstico como internacional. Ele introduziu novas categorias de representação e interpretação do mundo, fazendo com que os atores (economistas, políticos, agências burocráticas, grupos sociais) passassem a interpretar e definir seus próprios interesses por intermédio daquelas categorias.

Por fim, é importante verificar de que forma as inovações teóricas já produzidas pela literatura internacional, aqui sumariamente apresentadas, podem contribuir para uma análise da influência das idéias sobre a formulação da política externa brasileira contemporânea. As abordagens que trabalham com mecanismos institucionais como variáveis explicativas nos parecem, nesse sentido, bastante 
relevantes. Como já observamos anteriormente, as crenças que se apresentam como as mais enraizadas e com maior continuidade em nosso comportamento diplomático - realismo, pacifismo, não-intervencionismo, respeito ao Direito Internacional, aspiração a desempenhar um papel internacional protagônico - se cristalizaram em um período em que se assiste, também, ao progressivo fortalecimento institucional do Itamaraty. Tudo indica, portanto, que tais idéias se incorporaram ao desenho e recursos organizacionais daquela instituição desde muito cedo. Aquela institucionalização foi ainda reforçada, na década de 40, com a criação do Instituto Rio Branco, que também significa o momento em que o ministério ganha absoluto controle sobre os processos de seleção, recrutamento e treinamento de seus quadros. (Cheibub, 1982) Um exame mais acurado dessas diversas etapas de profissionalização e socialização dos diplomatas - isto é, daqueles a quem cabe, como função burocrática, formular e implementar a diplomacia do país - poderá ser bastante reveladora no sentido de apontar os mecanismos pelos quais o "acervo diplomático permanente”, percebido como produto de uma tradição de ação diplomática, transforma-se ele próprio nas categorias cognitivas - as "visões de mundo" - por intermédio das quais nossos diplomatas apreendem e interpretam a realidade internacional.

Uma outra questão, igualmente ligada a mecanismos causais de natureza institucional, diz respeito ao papel-chave desempenhado pelo Itamaraty na formulação, decisão e implementação da política externa. Aqui, trata-se de investigar a relação entre essa instituição e outras agências burocráticas e/ou grupos sociais que participam, direta ou indiretamente, na formação daquela política. Se a instituição portadora das idéias institucionalizadas adquire controle hegemônico sobre a formação de políticas, como foi o caso do ministério, tudo indica que aquelas idéias também se transportarão para os padrões de interação e socialização dessa instituição com outras agências burocráticas e grupos de interesse presentes em sua esfera de atuação.

Cabe destacar que também as abordagens que trabalham com mecanismos causais não-institucionais - como nas hipóteses de idéias como "mapas de estrada”, ou como poderosas alavancas de coalizões políticas - podem se revelar úteis para uma análise da influência das idéias na política externa brasileira. Ambas as hipóteses podem ser iluminadoras para uma compreensão daquela influência em períodos em que os mecanismos institucionais são mais frágeis ou menos insulados, e que a condução das relações exteriores do país se apresenta não só como uma tarefa centralizada no Itamaraty mas também como objeto de disputa das elites políticas domésticas.

Por fim, como já foi frisado, idéias não são apenas “passivas” mas adquirem um papel ativo quando adentram a arena política, introduzindo novas categorias cognitivas que permitem aos atores a redefinição de seus interesses. Assim, em uma visão de longo prazo, a interação entre os mecanismos causais acima delineados 
pode conceder às idéias um papel ativo e influente na constituição histórica de identidades e preferências da política externa brasileira.

\section{3 - Uma proposta de análise: a atuação do Brasil na Liga das Nações e na ONU}

Como observa Hurrell (s.d.), a análise da interação entre os níveis cognitivo e comportamental demanda a definição de algumas questões de natureza metodológica. Primeiro, a referência às idéias, valores e identidades historicamente construídas portadas pelos atores não se pode constituir em uma simples descrição de visões e discursos desconexos, cabendo ao analista dar a sua própria interpretação a tais discursos e fornecer um quadro de análise. Ao mesmo tempo, contudo, é necessário que essa interpretação faça sentido em termos das idéias, valores e significados dos próprios atores, ou seja, é necessário que se conceda aos atores a capacidade real de "acreditar" em suas idéias e de atuar motivados por essas últimas. Esse procedimento metodológico, aparentemente banal, é, de fato, imprescindível se se quer evitar o reducionismo da noção de idéias como meros "cabides".

Do ponto de vista de nossa proposta, a análise sobre a influência das idéias na política externa brasileira contemporânea deve obedecer a duas etapas que, embora distintas, são metodologicamente complementares. Em uma primeira etapa, é necessário reconstruir as principais crenças e idéias presentes em nosso discurso diplomático (aqui pensado em sentido amplo, e não apenas em termos dos discursos “oficiais”) através de uma análise de conteúdo orientada por três componentes fundamentais:

a) as concepções sobre a natureza (características intrínsecas) e a estrutura (relações de poder e/ou normas de funcionamento) do sistema internacional;

b) as concepções sobre a inserção do Brasil nesse último, com atenção especial às noções de papel, status e pertencimento. (Vertzberger, 1990) As duas primeiras estão diretamente interligadas, dependendo igualmente do primeiro componente (concepções sistêmicas), na medida em que as definições de papel e status têm necessariamente que levar em consideração o comportamento de outros atores internacionais, bem como as normas e/ou recursos de poder que regulam aquele comportamento. Já a noção de pertencimento liga-se diretamente ao terceiro componente; qual seja:

c) as concepções sobre identidade nacional e a forma pela qual esta se manifesta no comportamento externo, projetando sobre este determinados atributos (culturais, étnicos, demográficos, geográficos, político-econômicos) que são apresentados como relativamente permanentes.

Numa segunda etapa, a análise deve estabelecer as conexões entre o conteúdo cognitivo do discurso diplomático e a formulação da política externa, através do desvendamento dos mecanismos causais que explicam a influência de 
crenças e idéias sobre o processo de formação de políticas. Como já foi sugerido na seção anterior, a literatura internacional já desenvolveu, nesse sentido, uma série de abordagens que podem se revelar úteis para uma análise da política externa brasileira contemporânea.

\section{Um recorte empírico:}

Nossa proposta é a de concentrar a análise do papel das idéias na diplomacia brasileira sobre a atuação do Brasil na Liga das Nações e em sua sucessora, a Organização das Nações Unidas (ONU). Esse recorte empírico se justifica, em primeiro lugar, pelas próprias características da Liga e da ONU que, por serem organismos multilaterais, universais e voltados para a promoção de um certo tipo de "ordem" internacional, permitem recuperar o aspecto mais genérico das formulações diplomáticas brasileiras. Além disso, deve-se destacar o fato de que em ambas as organizações o Brasil desenvolveu aspirações a um papel internacional protagônico em momentos históricos totalmente distintos. Estamos nos referindo, aqui, às postulações brasileiras a ser membro permanente do Conselho Executivo da Liga, no período 1921/1926; à candidatura brasileira a um assento permanente no Conselho de Segurança da ONU, em 1944/45; e à renovação dessa candidatura em período recente. Como será demonstrado com mais detalhes adiante, chama atenção o fato de que em todos esses momentos as pretensões brasileiras tenham se apoiado em argumentos diplomáticos bastante semelhantes (ainda que, naturalmente, renovados de acordo com as características do país em cada época), o que se constitui em um importante indicador da persistência de certas crenças a respeito de quais devam ser nosso papel, status e pertencimento no plano internacional. Vale destacar, ainda, que embora os contextos domésticos dos três períodos sejam diferenciados, os contextos internacionais têm em comum o fato de se constituírem em momentos de grandes transformações estruturais no sistema internacional - o que, certamente, aumenta o grau de incerteza com que operam os atores dentro desse sistema.

\section{1) O Brasil na Liga das Nações (1921/26)}

Signatário do Tratado de Versalhes, que instituiu o pacto fundador da Liga, e eleito como membro rotativo para o Conselho Executivo da organização por dois mandatos consecutivos, o Brasil aproveitou o debate em torno da reformulação daquele Conselho - cujo objetivo era o de abrigar a Alemanha - para lançar sua candidatura a membro permanente. ${ }^{11} \mathrm{~A}$ argumentação da diplomacia brasileira baseava-se, então, no prestígio internacional de que o país já desfrutava, produto de atributos nacionais (dimensões continentais e demográficas, peso dentro da América do Sul); de uma já consolidada tradição diplomática (pacifismo, defesa da 
igualdade soberana das nações, respeito ao Direito Internacional) e mesmo do fato de ter sido a única nação latino-americana a participar militarmente da I Guerra Mundial. Desse ponto de vista, a candidatura brasileira se apresentava como “natural”, tendo em vista a posição única ocupada pelo país na América do Sul e suas fortes ligações com os EUA e a Europa, que lhe conferiam uma posição de prestígio dentro da Liga.

Apesar da evidente frieza das grandes potências, o país lançou-se em uma intensa campanha e buscou fórmulas que viabilizassem sua candidatura, chegando inclusive a apresentar-se como o candidato das Américas - proposta à qual se opuseram abertamente os países americanos, a começar pelos próprios EUA . O impasse então criado só se resolveu mediante a retirada do Brasil do Conselho e da própria Liga, em um episódio que gerou atritos entre o então representante do Brasil no organismo, Afrânio de Mello Franco, e o chanceler Félix Pacheco, apoiado pelo presidente Arthur Bernandes. ${ }^{12}$

O mesmo episódio, por sua vez, é bastante revelador do fato de que, nesse momento, os principais formuladores da diplomacia brasileira não eram diplomatas profissionais (de resto, a própria carreira ainda não está consolidada) e que o papel do Itamaraty, à época ainda se recuperando da lacuna deixada pelo desaparecimento da liderança carismática de Rio Branco, era reduzidíssimo (Cheibub, 1982). Os atores-chave são, portanto, representantes das diversas facções da elite política, como os já mencionados Afrânio de Mello Franco, Félix Pacheco e Arthur Bernardes, e ainda figuras proeminentes da vida política que desempenharam missões junto à Liga, como Raul Fernandes e Pandiá Calógeras.

Por outro lado, a bibliografia que analisa mais detalhadamente esse aparente “fiasco" da diplomacia brasileira na I República tende a classificá-lo como um típico produto da misperception de nossas elites dirigentes, somada à necessidade do autocrático governo Bernardes de instrumentalizar a política externa para fins de legitimação política doméstica (Cervo e Bueno, 1992; Garcia, 1994; Rodrigues e Seitenfus, 1995). Hilton (1980) vai um pouco além, assinalando que a atuação brasileira na Liga apoiava-se em um universo mais geral de crenças daquela elite a respeito de nossa inserção internacional, e no qual o Brasil era visto como um país solitário e isolado dentro da América Latina, cercado por vizinhos hostis, e por isso destinado a buscar um "lugar ao sol" no concerto das grandes potências.

Na verdade, como já assinalamos em nossa crítica aos estudos sobre misperception, não se trata propriamente de discordar desse diagnóstico mas sim de entender porque a misperception ocorre. Nesse sentido, uma análise do período poderia se beneficiar dos modelos que tratam da influência de idéias sobre a adoção de políticas através de mecanismos causais como "mapas de estrada” e "alavancas" de coalizões políticas domésticas. 
2) O Brasil na ONU-I (1944/47)

O Brasil renova sua postulação a um assento permanente no Conselho de Segurança da então em processo de criação Organização das Nações Unidas (ONU). ${ }^{13}$ Agora, esta se fundamenta na natureza e extensão da participação política, econômica e militar brasileira no esforço de guerra aliado - que envolvera, inclusive, o envio da Força Expedicionária Brasileira (FEB); na noção de uma "aliança especial“" com os EUA e, ainda, na crença de que o país tinha um importante papel a desempenhar nas conversações de paz e na reorganização do sistema internacional no pós-guerra. Persistia, também, a crença de que o país seria "especial” dentro da América do Sul, demandando, portanto, tratamento diferenciado. A posição ambígua dos EUA e, sobretudo, a forte oposição britânica e soviética frustraram uma vez mais a pretensão do Brasil, que teve que se contentar com a eleição para uma cadeira de membro não permanente do Conselho para o biênio 1946/47. ${ }^{14}$ Por outro lado, nesse momento a formulação da política externa continua concentrada na elite que controla postos-chave dentro do governo estado-novista, como o próprio Getúlio Vargas e personagens como Oswaldo Aranha (ministro das Relações Exteriores até 1944), Góes Monteiro (chefe do Estado-Maior das Forças Armadas) e Eurico Gaspar Dutra (ministro da Guerra). O peso do Itamaraty ainda está bastante associado à liderança de Oswaldo Aranha, mas cabe registrar a institucionalização crescente do ministério e da carreira diplomática, patenteada, inclusive, na criação do Instituto Rio Branco em 1945 (Moura, 1980 e 1982; Cheibub, 1982).

Nas análises sobre o episódio, a demora brasileira em perceber que a postulação estava fadada ao fracasso é classificada, novamente, como produto de misperception, fosse essa alimentada pelas evasivas norte-americanas (Moura, 1982) ou pela saída do "realista” e "pragmático” Aranha do ministério em 1944 (McCann Jr., 1973). Contudo, Moura também registra um certo consenso, entre elites dirigentes civis e militares, de que o país poderia aspirar a um papel internacional relevante no pós-Guerra, o que determinou inclusive a insistência no envio da FEB. Nesse sentido, pode-se considerar, para esse período, a conveniência de uma abordagem que considere o papel de idéias institucionalizadas, idéias que atuam como "mapas de estrada" e ainda idéias que permitem ou consolidam arranjos intraburocráticos.

\section{3) O Brasil na ONU-II (1994/98)}

Uma vez mais, o Brasil aproveita o debate em torno da revalorização e da reforma do Conselho de Segurança, que se tornou particularmente agudo no pósGuerra Fria, para relançar sua candidatura a membro permanente. ${ }^{15}$ Muito embora a questão já viesse sendo cogitada desde fins dos anos 80, a candidatura só foi 
oficializada em 1994, diante da percepção do Itamaraty de que o $50^{\circ}$ aniversário da ONU daria um novo impulso no debate já em curso sobre a reforma do sistema das Nações Unidas como um todo e, em especial, do Conselho de Segurança (Amorim, 1996 e 1997).

Dessa feita, a argumentação brasileira baseava-se, de um lado, na constatação de que a composição do Conselho teria que ser ajustada às novas realidades políticas e econômicas do mundo pós-Guerra Fria, com base em critérios que aumentassem sua representatividade, legitimidade e eficácia. Por sua vez, as credenciais brasileiras a um assento permanente fundamentam-se, uma vez mais, na tradição diplomática, no perfil internacional atuante e diversificado e em um conjunto de atributos associados ao país (dimensões geográficas, características étnico-culturais, regime político, dimensão econômica, peso regional específico). Também uma vez mais, a aspiração a um novo status dentro do Conselho de Segurança é parte de uma crença mais geral de que o Brasil tem papel protagônico a desempenhar nos processos decisórios e regulatórios das relações internacionais contemporâneas, que têm como pano de fundo um sistema internacional em processo de transformações estruturais (Amorim, 1995, 1996 e 1997; Lampreia, 1995 e agosto 1997).

Contudo, as declarações oficiais também têm grande preocupação em frisar que o país "não está em campanha” nem faz disso uma "meta obsessiva” de sua política externa. Baseada em indicadores "objetivos” de projeção internacional, a candidatura brasileira é apresentada como "natural”. (Lampreia, s.d.; Amorim, 1997) Apesar de "não estar em campanha”, é fato que o tema tem sido intensamente abordado nos contatos bilaterais com outros países (incluindo aqueles de maior peso, isto é, os atuais membros permanentes do Conselho e países que também têm interesse na reforma, como Alemanha, China, Índia e África do Sul) a nível ministerial ou presidencial desde o governo Itamar Franco.

Mais recentemente, a candidatura brasileira voltou à cena impulsionada por três novos acontecimentos. Em primeiro lugar, a divulgação do chamado projeto Razali, resultado dos trabalhos do Grupo de Trabalho Informal da ONU que vem debatendo a reformulação do Conselho. ${ }^{16}$ Em segundo, o sinal positivo dado pelos EUA a uma ampliação que contemple a entrada de Alemanha, Japão e mais três países em desenvolvimento como membros permanentes. E, por fim, a divulgação da posição argentina, que defende a rotatividade dos novos membros permanentes e que é vista, de forma geral, como manifestação de oposição à candidatura brasileira. O Brasil, por sua vez, tem reagido à tese argentina através do argumento de que a rotatividade criaria uma terceira e discriminatória categoria de membros; e, ainda, de que escolha dos novos membros permanentes deve obedecer a critérios que levem em conta a projeção global dos candidatos, não sendo necessário que se conte, para tal, com o apoio de "consensos regionais" (Lampreia, setembro de 1997; Amorim, 1997). 
Paralelamente a todo esse processo, a diplomacia brasileira ainda se encontra sob forte comando do Itamaraty, não obstante os efeitos da redemocratização política. Quanto a esses últimos, deve-se destacar o fato de que agora o ministério tem que interagir não apenas com outras corporações burocráticas, mas com um leque muito mais diversificado de atores que inclui o Legislativo, os partidos políticos, grupos de interesse os mais variados - aí incluído o fenômeno novo das Organizações Não- Governamentais -, entidades da sociedade civil e a opinião pública em geral. Entretanto, se é verdade que para certas áreas da política externa essa diversificação teve conseqüências reais para o processo de formação de políticas (exemplos disso são as negociações dentro dos subgrupos de trabalho do MERCOSUL e o complexo trâmite no Congresso do novo Código de Propriedade Intelectual), em outras tal impacto é quase inexistente. De fato, uma das marcas da nova candidatura brasileira ao Conselho de Segurança é que ela vem sendo apresentada à sociedade como se fosse produto de um "consenso" em torno da defesa do "interesse nacional". E essa mesma sociedade tem demonstrado, se não apoio, ao menos indiferença para um tema que implica, de fato, ônus financeiro e militar para o país, como se a candidatura brasileira fosse tão "natural" aos olhos do público doméstico como o deveria ser aos dos outros países. ${ }^{17}$ Temos, portanto, um tipo de situação interessante para uma análise de como idéias institucionalizadas se tornam "mapas de estrada” e, simultaneamente, atuam como "alavancas" para alianças intraburocráticas - pois convém ressaltar que essa é uma área bastante sensível para a corporação militar, o que supõe algum nível de consulta ou negociação - e coalizões políticas.

\section{4 - Conclusões}

Esse trabalho pretendeu apresentar uma proposta de análise da influência de idéias sobre a formulação da política externa brasileira contemporânea. Inicialmente, procuramos demonstrar, através de um balanço bibliográfico e historiográfico, que a dimensão cognitiva do processo de formação de políticas vem sendo negligenciada na produção acadêmica sobre política externa brasileira. Isso se deve, em grande parte, ao incipiente diálogo entre aquela e a literatura internacional sobre teoria das relações internacionais, que desde o fim dos anos 50 desenvolveu uma subárea de análise de política externa.

A seguir, argumentamos que a literatura acadêmica internacional já vem há bastante tempo se voltando para a análise de mecanismos cognitivos. Concentrada inicialmente sobre os estudos de misperception, essa literatura vem se deslocando, atualmente, para a análise dos mecanismos causais que explicam a influência de idéias sobre a adoção de políticas. Nesse sentido, ela já desenvolveu uma série de modelos de alcance teórico parcial que se podem revelar úteis para uma análise da política externa brasileira contemporânea. Tal análise deve se pautar, primeiramente, pela reconstrução das crenças presentes no discurso diplomático 
para, a seguir, desvendar os mecanismos causais que explicam a influência daquelas crenças sobre a formulação de políticas.

Por fim, nossa proposta sugere como recorte empírico a atuação brasileira na Liga das Nações e na ONU, mais especificamente nos períodos em que o Brasil aspirou a participar dos núcleos decisórios centrais desses organismos (Conselho Executivo da Liga e Conselho de Segurança da ONU), restritos às grandes potências. Nossa hipótese, nesse caso, é a de que tais aspirações indicam a persistência e a influência de crenças seminais no comportamento diplomático brasileiro.

Julho 1998

\section{Notas}

1 Esse artigo é em grande parte baseado em meu projeto de tese de doutorado, defendido junto ao Instituto Universitário de Pesquisas do Rio de Janeiro (IUPERJ) em 1997. Nesse sentido, gostaria de agradecer à orientação da professora Maria Regina Soares de Lima e aos valiosos comentários dos professores Marcos Figueiredo, José Murilo de Carvalho, César Guimarães e Mônica Herz. Ele é também produto de um projeto de pesquisa atualmente desenvolvido junto ao Centro de Pesquisa e Documentação de História Contemporânea do Brasil (CPDOC), da Fundação Getulio Vargas, que conta com o apoio financeiro do Programa de Apoio a Núcleos de Excelência (PRONEX). Na parte de levantamento de fontes, contei com a colaboração de Bruno de Moura Borges, bolsista do CPDOC/PIBIC-CNPq.

2 A esse respeito, ver, por exemplo, as obras de Pandiá Calógeras, A Política Exterior do Império. (Brasília, Fundação Alexandre de Gusmão/ Companhia Editora Nacional, 1989 - $1^{\text {a }}$ edição 1927); Hélio Vianna, História Diplomática do Brasil (São Paulo, Melhoramentos, 1961? - $1^{\text {a }}$ edição 1958); e Delgado de Carvalho, História Diplomática do Brasil (Rio de Janeiro, Companhia Editora Nacional, 1959). As duas últimas obras devem sua origem às “notas de cursos” ministrados pelos autores para alunos do Instituto Rio Branco em fase de preparação para a carreira diplomática e oficiais do Estado-Maior das Forças Armadas. Para uma análise historiográfica detalhada da produção intelectual brasileira no campo da História das Relações Internacionais e da História Diplomática, ver Cervo (1992) e Almeida (1993).

3 Ver, entre outros, os trabalhos de Paulo Schilling, O Expansionismo Brasileiro (São Paulo, Global, 1987); e Rui Mauro Marini, “Brazilian Sub-imperialism”, Monthly Review. (23(2), fev. 1972).

4 Exemplos desse pensamento geopolítico podem ser encontrados nas obras de Carlos de Meira Mattos, Brasil, Geopolítica e Destino (Rio de Janeiro, José Olympio, 1975); e Golbery do Couto e Silva, Geopolítica do Brasil (Rio de Janeiro, José Olympio, 1981).

5 Em relação a essa nova safra da produção acadêmica, ver os trabalhos de Carlos Estevão Martins. “A Evolução da Política Exterior Brasileira na Década 64/74”, Estudos CEBRAP (12, 1975); Celso Láfer, Paradoxos e Possibilidades (Rio de Janeiro, Nova Fronteira, 1982); Gerson Moura, Autonomia na Dependência: Política Externa Brasileira de 1935 a 1942 (1980); Mônica Hirst, “A Política Externa do Segundo Governo Vargas”, Sessenta Anos de Política Externa Brasileira 1930-1990 - vol. 1 (São Paulo, Cultura Editores/Núcleo de Pesquisa em Relações Internacionais da USP, 1996); Maria Regina Soares de Lima, “A Economia Política da Política Externa Brasileira: uma proposta de análise”, Contexto Internacional (12, jul./dez. 1990); e Amado Luiz Cervo e Clodoaldo Bueno, História da Política Exterior do Brasil (1992). 
6 O conceito de idéias está sendo utilizado, aqui, em sentido amplo. Ele compreende tanto crenças normativas (valores) como crenças causais ou instrumentais, isto é, crenças sobre relações de causa e efeito. Ele pode designar também uma doutrina, ou seja, um conjunto articulado e internamente coerente de crenças causais e normativas como, por exemplo, o realismo. A esse respeito, ver Keohane e Goldstein (1993).

7 Ver os trabalhos seminais de Kenneth Boulding, The Image (Ann Arbor, University of Michigan Press, 1956); Alexander George, "The causal nexus between cognitive beliefs and decisionmaking behavior: the 'operational code' belief system”, Psychological Mode in International Politics (Boulder, Westview, 1979); Perception and Misperception in International Politics (Princeton, Princeton University Press, 1976); O. Holsti, “The belief system and national images: a case study”, Journal of Conflict Resolution (6, 1962); Robert Axelrold, Structure of Decision (Princeton, Princeton University Press, 1976); e Michael Brecher, The Foreign Policy System of Israel: Setting, Images, Process (London, Oxford University Press, 1972).

8 Yee estabelece uma crítica, por exemplo, à abordagem de “códigos operacionais” construída por Alexander George e o seu procedimento metodológico de process tracing, pelo qual se busca traçar todas as etapas intervenientes através das quais as crenças influenciam o comportamento do decision maker, as quais envolveriam a receptividade desse último em relação à informação; sua definição da situação; a identificação e avaliação das opções possíveis e, por fim, a escolha de um curso de ação. Nas palavras de Yee: "Despite its plausibility, however, knowing the various intervening cognitive steps taken by the decison makers does not reveal how ideas and beliefs caused them to take those steps. A distinction exists between citing the ways in which something occurs and knowing why it occurs in those ways. Delineating the 'steps in the process by means of which' beliefs influence and shape the cognitive operations of the decision makers does not reveal how these beliefs influenced decision makers to take those steps." (1996, p. 77)

9 A esse respeito, ver, por exemplo, o artigo de Alexander Wendt, “The Agent-Structure Problem in International Relations Theory”, International Organization (41, summer 1987).

10 O conceito de "comunidades epistêmicas” desenvolvido por Peter Haas também se encaixaria em uma abordagem como a do tipo sugerido por Hall. Para uma exposição detalhada do mesmo, ver Haas, "Introdution: Epistemic Communities and Internacional Policy Coordination”, International Organization (46, winter 1992). Para uma abordagem das insuficiências do mesmo, ver Jacobsen (1995) e Yee (1996).

11 O Brasil foi eleito em 1921 e 1925 como membro rotativo do Conselho Executivo da Liga. Os membros ocupando assentos permanentes, à época, eram França, Grã-Bretanha, Itália e Japão. Os EUA, apesar de terem um assento permanente assegurado, não chegaram a assumi-lo porque o Congresso norte-americano se negou a ratificar o Pacto fundador da Liga. Em 1924, já como parte da campanha ao assento permanente, o Brasil criou uma missão de representação permamente junto à Liga e elevou-a à categoria de embaixada.

12 Uma descrição detalhada do episódio pode ser encontrada em Rodrigues e Seintenfus (1995); e Garcia (1994).

13 O Conselho de Segurança da ONU, criado juntamente com a organização em 1945, é composto por cinco membros permanentes com direito a veto - EUA, URSS (atualmente Rússia), Inglaterra, França e China - e dez rotativos, eleitos por períodos de dois anos.

14 A respeito das ambigüidades na postura dos EUA com relação às aspirações brasileiras de ocupar um assento permanente no Conselho, ver Moura (1982).

15 Para uma análise da evolução do novo papel assumido pelo Conselho de Segurança no pósGuerra Fria, ver Láfer e Fonseca Jr., 1994; e Amorim, 1996.

16 O referido GT, que se intitula formalmente "Grupo de Trabalho aberto sobre a representação eqüitativa a a ampliação do Conselho de Segurança”, iniciou seus trabalhos em 1995. Presidido por Razali Ismail, representante da Malásia que foi também o presidente da $51^{\mathrm{a}}$ sessão da 
Assembléia Geral, o Grupo submeteu à atual sessão um projeto de resolução, ainda não votado, que prevê a inclusão de cinco novos membros permanentes (sem direito a veto) e cinco nãopermanentes. Além disso, o projeto estabelece que a definição do novo formato do Conselho deve preceder a escolha dos novos membros, a ser submetida à Assembléia Geral. Ver "Assembly president ...”, 1997; Lampreia, agosto 1997; e “Security Council reform...”, 1997.

17 É significativo, nesse sentido, que o ministro Luís Felipe Lampreia frise que "essa não é e não pode tornar-se uma questão partidária ou de política interna, nem um objetivo ou um alvo de manifestaçãoes de natureza eleitoral. Estamos falando de um interesse permanente do Brasil .” (grifo nosso) No entanto, ele próprio admite que "uma participação mais intensa do Brasil nas Nações Unidas teria também conseqüências práticas e financeiras”, tais como o aumento da contribuição financeira e um maior engajamento militar nas Operações de Paz. Ver Lampreia, agosto 1997.

\section{Bibliografia}

ALMEIDA, Paulo Roberto de. "Estudos de relações internacionais do Brasil: etapas da produção historiográfica brasileira, 1927/1992”. Revista Brasileira de Política Internacional. 36(1), 1993.

AMADO, Rodrigo (org.). Araújo Castro. Brasília: Editora da UnB, 1982.

AMORIM, Celso. “O Brasil e o Conselho de Segurança da ONU”. Política Externa. São Paulo, 3(4), março/abril/maio 1995.

. “A Reforma da ONU”. Estudos Avançados - Série Assuntos Internacionais 43. São Paulo: Instituto de Estudos Avançados/USP, março 1996.

—_. Entrevista concedida à Alexandra de Mello e Silva. Nova Iorque, novembro de 1997.

BRASIL, Ministério das Relações Exteriores. A Palavra do Brasil nas Nações Unidas 1946-1995. Brasília: FUNAG, 1995.

CERVO, Amado Luiz. “A Historiografia Brasileira das Relações Internacionais”. Revista Interamericana de Bibliografia. 42(3), 1992.

—. (org.) O Desafio Internacional. A Política Exterior do Brasil de 1930 a nossos dias. Brasília: Editora da UnB, 1994.

— e BUENO, Clodoaldo. História da Política Exterior do Brasil. São Paulo: Ática, 1992.

CHEIBUB, Zairo Borges. Diplomatas, Diplomacia e Política Externa: aspectos do processo de institucionalização do Itamaraty. Rio de Janeiro: dissertação de mestrado - IUPERJ, 1984.

COLÓQUIO Carta de São Francisco: Cinqüenta Anos Depois. São Paulo: Instituto de Estudos Internacionais/ USP, junho 1995.

ELSTER, Jon. Peças e Engrenagens das Ciências Sociais. Rio de Janeiro: Relume-Dumará, 1994.

FONSECA JR., Gelson. "Estudos sobre Política Externa no Brasil: os Tempos Recentes (1950/ 1980)”. In FONSECA JR. e LEÃO (orgs.). Temas de Política Externa Brasileira. Brasília: FUNAG/IPRI - Ática, 1989.

GARCIA, Eugênio Vargas. “A candidatura do Brasil a um assento permanente no Conselho da Liga das Nações”. Revista Brasileira de Política Internacional. Brasília, 37(1), 1994.

GARROT, Emmanuel. “Un regard sur l'historiographie de la politique extérieure brésilenne aux Xxe siècle”. In . Dennis Rolland (coord.). Le Brésil e Le Monde. Pour une histoire des relations internationales de puissances émergentes. Paris: L’Harmattan, 1998.

GOLDSTEIN, Judith e KEOHANE Robert O. "Ideas and Foreign Policy: An Analytical Framework”. in GOLDSTEIN e KEOHANE (eds.). Ideas and Foreign Policy: Beliefs, Institutions and Political Change. Ithaca/London: Cornell University Press, 1993.

GOMES, Henrique de Souza. “A Conferência de São Francisco e a atuação de Leão Veloso”. Revista Brasileira de Política Internacional. Rio de Janeiro, XIII(49/50), março/junho de 1970. 
HALL, Peter A. (ed.). The Political Power of Economic Ideas: Keynesianism across Nations. Introduction and Conclusion. Princeton: Princeton University Press, 1989.

HERZ, Mônica. “Análise Cognitiva e Política Externa”. Contexto Internacional. Rio de Janeiro, 16(1), jan./jun. 1994.

HILL, Christopher e LIGTH, Margot. “Foreign Policy Analysis”. In LIGHT e GROOM (ed.) . International Relations - a Handbook of Current Theory. London: Printer Plubishers, 1985.

HILTON, Stanley. "Brazil and the Post-Versailles World: Elite Images and Foreign Policy Strategy, 1919-1929”. Journal of Latin American Studies. 12 (2) november 1980.

HIRST, Mônica e PINHEIRO, Leticia. A Política Externa do Brasil em dois Tempos. Buenos Aires: FLACSO, maio 1995.

HURRELL, Andrew. Progressive Enmeshment, Hegemonic Imposition or Coercive Socialization? Understanding Policy Change in Brazil. s.l., mimeo, s.d.

IKENBERRY, John. “Creating Yesterday’s Postwar Order: Keynesianism, the 'New Thinking' and the Anglo-American Settlement”. in Keohane and Goldstein, op. cit.

JAGUARIBE, Hélio. O Nacionalismo na Atualidade Brasileira. Rio de Janeiro: ISEB, 1958.

JACOBSEN, John Kurt. "Much Ado About Ideas - The Cognitive Factor in Economic Policy". World Politics, 47, january 1995.

LAFER, Celso e FONSECA JR., Gelson. "Questões para a Diplomacia no Contexto Internacional das Polaridades Indefinidas (Notas analíticas e Algumas Sugestões)”. In FONSECA JR. e CASTRO (orgs.). Temas de Política Externa Brasileira II. São Paulo: IPRI/Paz e Terra, 1994.

LAMPREIA, Luiz Felipe. “Um decálogo para reflexão”. Folha de São Paulo, 25 de junho de 1996.

_. "Diplomacia ganha a cara do Brasil”. Entrevista concedida ao Zero Hora, 01 de outubro de 1995.

—. O Brasil e a reforma das Nações Unidas. Comunicado à imprensa, s.d.

—. "A reforma do Conselho de Segurança”. Folha de São Paulo, 31 de agosto de 1997.

. Statement by the Minister of Foreign Relations of Brazil at the opening of the General Debate of the 52nd Session of the United Nations General Assembly. New York, September 22, 1997.

- Discurso do Ministro das Relações Exteriores por ocasião do almoço que oferece aos Chanceleres e Chefes de Delegação do Grupo Latino-Americano e do Caribe nas Nações Unidas. New York, 23 de setembro de 1997.

LIMA, Maria Regina Soares de. "Enfoques Analíticos de Política Exterior: el caso brasileño”. In RUSSEL (org.). Enfoques Teoricos y Metodologicos para el Estudio de la Política Exterior. Buenos Aires: GEL, 1992.

—_. "Ejes Analíticos y Conflitos de Paradigmas en la Política Exterior Brasileña”. América Latina/ Internacional. Buenos Aires, 1(2), 1994.

LITLLE, Richard e SMITH, Steve (ed.) . Belief Systems and International Relations. Oxford/New York: Basil Blackwell, 1988.

McCANN JR., Frank D. The Brazilian-American Alliance - 1937/1945. Princeton: Princeton University Press, 1973.

MOURA, Gerson. Autonomia na Dependência - A Política Externa Brasileira de 1935 a 1942. Rio de Janeiro: Nova Fronteira, 1980.

—. Brazilian Foreign Relations 1939 - 1950: the changing nature of Brazil - United States relations during and after the Second World War. London: University College - Ph. D. dissertation, 1982.

PINHEIRO, Leticia. Foreign Policy Decision-making process under the Geisel administration (1974/ 1979) - the diplomats, the military and the presidency. London School of Economics, Ph. D. dissertation, 1994.

RODRIGUES, José Honório e SEITENFUS, Ricardo A. S. Uma História Diplomática do Brasil (1531 -1945). Rio de Janeiro: Civilização Brasileira, 1995.

SILVA, Alexandra de Mello e. "O Brasil no Continente e no Mundo: Atores e Imagens na Política Externa Brasileira Contemporânea”. Estudos Históricos. Rio de Janeiro, (15), jan./jun. 1995. 
UNITED NATIONS. Assembly president proposes increase in Security Council membership to 24 by adding 5 permanent, 4 non-permanent members. Press Release GA/9228, 20 march 1997.

—. "Security Council Reform Continues to Spur Debate”. United Nations Chronicle. 34(3), 1997.

VERTZBERGER, Yaacov. The World in their Minds - Information Processing, Cognition and Perception in Foreign Policy Decision Making. Stanford: Stanford University Press, 1990.

YEE, Albert S. "The causal effects of ideas on policies”. International Organization. 50(1), winter 1996.

\section{Resumo}

Esse artigo apresenta uma proposta de análise da influência de idéias sobre a formulação da política externa brasileira contemporânea focalizada em nossa atuação na Liga das Nações e na ONU. Em ambos os organismos, o país desenvolveu aspirações a um papel internacional protagônico, o que acreditamos ser indicador da recorrência, no discurso diplomático, de certas crenças a respeito de quais devam ser o nosso papel, status e pertencimento a nível internacional. Destacamos, ao mesmo tempo, que uma análise desse tipo não pode se limitar a reconstruir o discurso diplomático, mas deve também procurar desvendar os mecanismos causais que explicam o impacto daquelas crenças sobre a formação de políticas. Nesse sentido, a literatura acadêmica internacional já desenvolveu uma série de abordagens que podem se revelar úteis para um estudo da diplomacia brasileira.

\section{Abstract}

This article presents an analytical framework of the influence of ideas over Brazilian contemporary foreign policy formulation, focusing on Brazilian performance at the League of Nations and the United Nations. In both organizations, Brazil has aspired to perform an international leading role, which, as we argue, constitutes an indicator of the recurrence, in the diplomatic discourse, of certain beliefs about what should be Brazilian status, role and belonging in the international arena. Simultaneously, the article argues that such analysis should not only reconstruct the diplomatic discourse but also try to unfold the causal mechanisms that explain the impact of those beliefs in the policymaking process. In this sense, the international academic literature has already developed a series of approaches that might prove useful to the study of Brazilian diplomacy.

Palavras-chave: Política Externa Brasileira. Liga das Nações. ONU. Conselho de Segurança da ONU. Análise de Política Externa. Análise Cognitiva.

Key-words: Brazilian Foreign Policy. League of Nations. UN. UN Security Council. Foreign Policy Analysis. Cognitive Analysis. 